b. 油焼入後焼戻しの場合

$$
\text { Al } 8 \cdot 0 \pm 0.2 \% \text { C } 2 \cdot 0 \pm 0.1 \%
$$

2. 最も優れた磁性の得られれる合金組成の範囲は， Fe-A1-C 状態図の $r$ 相領域において, $(r+\mathrm{K})$ または $(r+C)$ 相とのそれぞれの境界線に近い部分に存在し ている.

3. 添加元素の影留については，少量 $(0.5 \sim 2 \%)$ 添 加して，磁性に好影響を与えるものとして，Ni， Cu, Sn などが挙げられるが，3\% 以上添加すると，Co を除い
ては，磁性に好影響を与えない，

4. MT磁石の磁性に特に悪い影嘅をおよ心添加元 素は，Si， Ti， V，BeおよびBである. 保磁力のみを 上昇せしめる元素は， $\mathrm{Cr}$ および $\mathrm{Mn}$ である.

(昭和 31 年9月日寄稿)

文献

1) K. Löhberg, W. Schmidt: Arch. f. Eisenhüttenwes. $12(1937 / 38) 607$

\title{
$\mathrm{TiO}_{2}$ を含有する鉱涬による微細化黒鉛鋳鉄に関する研究 $(\mathrm{VII})^{\dagger}$
}

(S-H 鋳鉄中の Ti に関する熱力学的考察)

沢村 宏*.盛利貞**.津田㫤 利***

\section{INVESTIGATION ON CAST IRON HAVING REFINED GRAPHITE PRODUCED BY MELTING CAST IRON COVERED WITH SLAG CONTAINING $\mathrm{TiO}_{2}$ (VII)}

\author{
(Thermodynamic Study on the Ti Contained in S-H Cast Iron)
}

\section{Hiroshi Sawamura Dr. Eng., Toshisada Mori Dr. Eng. and Masatoshi Tsuda}

\section{Synopsis:}

A thermodynamic study was carried out on the equilibrium of the reactions $\mathrm{C}+\mathrm{Ti}=\mathrm{TiC}(\mathrm{s})$ and $\mathrm{Ti}+\mathbf{N}=\mathrm{TiN}(\mathrm{s})$ in a cast iron melt containing $4 \% \mathrm{C}, 0.25 \% \mathrm{Ti}, 0.03 \% \mathrm{~S}, 0.008 \% \mathrm{~N}$, and $0.002 \% \mathrm{O}$ under some assumptions. The formation temperatures of $\mathrm{TiO}_{2}(\mathrm{~s}), \mathrm{TiO}(\mathrm{s})$ and TiS(s) in the same melt were also determined by calculation. $\mathrm{Ti}$ in the form of $\mathrm{TiC}$ (s) was found to be about $80 \%$ of the total $\mathrm{Ti}$ content at $1400 \sim 1450^{\circ} \mathrm{C}$. Though the result was not accurate, the behaviour of $\mathrm{Ti}$ in the melt during its slow cooling from about $1800^{\circ} \mathrm{C}$ could be apploximately estimated.

\section{I. 緒 言}

S-H 鋳鉄は多少にかかわらずつねに Ti を含有して いるととはすでに報告したとおりであるリ。 この Ti は S-H 鋳鉄製造の際，普通成分の鋳鉄浴に含 $\mathrm{TiO}_{2}$ 愹漳 処理を施とした場合に螾㵏から鉄鋳浴中に移行してくる ものである゙2. 著者等》はかようにして移行してきた Ti が S-H 鋳鉄中において主として純粋に近い TiC 単体 の形態で存在することを分析によつて確めた：本報では S-H 鋳鉄浴中の Ti の挙動を推定する一手段として浴 中に生成する $\mathrm{TiC}, \mathrm{TiN}$ 等の平䘖関係を熱力学的に計 算した結果について述べる. 計算を行うに当つては予め S-H 鋳鉄の成分を決めておかなければならない. S-H
鋳鉄は特に高炭素である点に特徴があり，今までの実物 結果によると $\mathrm{Ti}$ はC 含有量が $3 \cdot 5 \sim 4 \cdot 0 \%$ の場合，普 通約 $0.2 \sim 0.3 \%$ である場合が多く，またNは従来の分 析例によると平均 $0.008 \%$ 程度である.なお S-H 鋳鉄

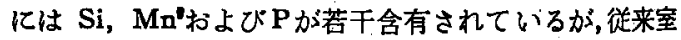
温より $1800^{\circ} \mathrm{C}$ のうな高温度にわたる温度範囲におい て炭化 Ti の安定度がてれらの元素の炭化物のそれより 遥かに大であり，窒化 Ti の安定度についても同様である ことが知られているから，とれらの元素の存在を無視し てとれらの元素以外の S-H 鋳鉄浴の成分を Table 1

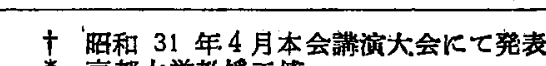
宗都大学教授工柯 京都大学助散授工博

****京都大学化学研独所
} 
に示すように定めて計算を行うととにした。

Table 1. The presumed composition of $\mathrm{S}-\mathrm{H}$ cast iron melt.

\begin{tabular}{c|c|c|c|c}
\hline $\mathrm{C} \%$ & Ti $\%$ & $\mathrm{~S} \%$ & $\mathrm{~N} \%$ & $\mathrm{O} \%$ \\
\hline $4 \% 0$ & 0.25 & 0.03 & 0.008 & 0.002 \\
\hline
\end{tabular}

II. (1) $\underline{\mathbf{T}}+\underline{\mathbf{C}}=\mathbf{T i C}(\mathrm{s})$ の平衡

$\mathrm{Ti}(\mathrm{s})+\mathrm{C}(\mathrm{g})=$ ' $^{\mathrm{TiC}}$ ' (s)*s.c.;

$\Delta F_{1}^{0}=-44600+3^{*} 16 \mathrm{~T} \quad 1150 \sim 2000^{\circ} \mathrm{K} \cdots(1)^{4)}$

ただし 'TiC' は TiC 化合物が Ti(s) 亿対して固溶 限度を有することを示し添字 s.c. は固溶限度を有する が(1) 式の計算に際しては純䊉の TiC 化合物に関す る数值を用いたことを示している.

$$
\mathrm{C}(\mathrm{g})=\mathrm{C}_{l}(4 \%) \text {; }
$$

$\Delta \mathrm{F}_{2}^{0}=6400-4 \cdot 83 \mathrm{~T} \quad 1548 \sim 2273^{\circ} \mathrm{K}$

(2) 式の $\Delta \mathrm{F}_{2}^{0}$ は $\mathrm{C}$ の標準状熊を $\mathrm{C}(\mathrm{g})$ にとり $\underline{\mathrm{C}}_{l}$ (4\%) の活量によつて計算された式である.

$\operatorname{Ti}(\mathbf{s})=\operatorname{Ti}_{l}(1 \%) ; \quad \Delta \mathrm{F}_{3}^{0}=-7000-11 \cdot 0 \mathrm{~T} \cdots(3)^{5)}$

（3）式は $1600^{\circ} \mathrm{C}$ の譗鉄中に Ti が含有される場合, 無限稀薄溶体における $\mathrm{Ti}$ の活量係数を $\gamma_{1873}=0^{\circ} 05^{5}$ ), 溶体を正則溶液と仮定しまた Ti の熔骶熱を 4200Cal/ $\mathrm{mol}^{\mathrm{b})}$ と仮定して計算した式である.

(1)-(2)-(3)

$$
\begin{aligned}
& \underline{\mathrm{Ti}}_{l}(1 \%)+\underline{\mathrm{C}}_{l}(4 \%)=\mathrm{TiC}(\mathrm{s}) ; \\
& \Delta \mathrm{F}_{4}^{\mathrm{0}}=-44000+18.99 \mathrm{~T}
\end{aligned}
$$

また

$$
\begin{aligned}
& \operatorname{Ti}_{l}(1 \%)=\operatorname{Ti}_{l}(0 \cdot 25 \%) ; \\
& \Delta \mathrm{F}_{5}^{0}=4 \cdot 57.5+\log 0 \cdot 25=-2 \cdot 75 \mathrm{~T}
\end{aligned}
$$

(4) $-(5)$

$$
\begin{aligned}
& \mathrm{Ti}_{l}(0 \cdot 25 \%)+\underline{\mathrm{C}}_{l}(4 \%)=\mathrm{TiC}(\mathrm{s}) ; \\
& \Delta \mathrm{F}_{\mathrm{B}}^{0}=-44000+21 \cdot 74 \mathrm{~T} \ldots \ldots \ldots \ldots \ldots . .
\end{aligned}
$$

$\mathrm{Ti}, \mathrm{C}$ を含有する熔銑化対する $\mathrm{TiC}$ の溶解度がさわめ て小であると仮定すれば $\Delta \mathrm{F}_{6}^{0}=0$ ならしめる温度 (1751 $\left.{ }^{\circ} \mathrm{C}\right)$ において (6) 式は平矢状態にあり，したがつてこ の温度 $\mathrm{T} i=0.25 \%, \underline{\mathrm{C}}=4.0 \%$ 含有する塔銑の液 相面の温度を示すことになる. $1751^{\circ} \mathrm{C}$ 以下の任意の温 度における $\mathrm{Ti} ， \underline{C} ， \mathrm{TiC}$ の量を計算すると $\mathrm{Ti}=0.25$ \%のうちで TiC となつた Ti 量を $x \%$ とすると $\mathrm{TiC}$ となつたC量は $12 \cdot 01 / 47 \cdot 90 \cdot x \%$ である．後記の計算 桔果加ら明らかなとおり TiC が生成してもその量はき かめてわづかであり Cの変化はきわめて少ない.したが つて $=4 \%$ の場合の活量係数を $f$ で表わせば（6）式

证 *以下 $\operatorname{TiC}(\mathrm{s})$ と略記する.
の反応によつて変化するC量の範团では $f$ は定と考え て差支えない. 化したために生ずる自由エネルギーの変化は次式であた えられる。

$$
\begin{aligned}
& \underline{\mathrm{C}_{l}}(4 \%)=\underline{\mathrm{C}_{l}}\left\{\left(4-\frac{12 \cdot 01}{47 \cdot 90} x\right) \%\right\} ; \\
& \Delta \mathrm{F}_{7}^{0}=4 \cdot 575 \mathrm{~T} \log \begin{array}{c}
\left(4-\frac{12 \cdot 01}{47 \cdot 90} x\right) f \\
4 f
\end{array} \\
& =4 \cdot 575 \mathrm{~T} \log \begin{array}{c}
4 \mathrm{f}^{2} \cdot 01 \\
47 \cdot 90
\end{array} \\
& 4
\end{aligned}
$$

また

$$
\begin{aligned}
& \underline{\operatorname{Ti}}_{l}(0 \cdot 25 \%)=\underline{T i}_{l}\{(0 \cdot 25-x) \%\} ; \\
& \Delta \mathrm{F}_{8}^{0}=4 \cdot 575 \mathrm{~T} \log \frac{0.25-x}{0.25} \ldots \ldots .
\end{aligned}
$$

(6) $-(7)-(8)$

$$
\begin{gathered}
\operatorname{Ti}_{i}\{(0 \cdot 25-x) \%\}+\underline{\mathrm{C}}_{l}\left\{\left(4-\frac{12 \cdot 01}{47 \cdot 90} x\right) \%\right\}=\operatorname{TiC}(\mathrm{s}) ; \\
\Delta \mathrm{F}_{9}^{0}=-44000+21 \cdot 74 \mathrm{~T}-4 \cdot 575 \mathrm{~T}
\end{gathered}
$$$$
\times \log (0 \cdot 25-x)\left(\left(4-\frac{12 \cdot 01}{47^{*} \cdot 90} x\right)\right.
$$

例元ば， $\mathrm{T}=1200^{\circ} \mathrm{C}\left(1473^{\circ} \mathrm{K}\right)$ 亿求ける平兽值を求” るには (9) 式か（10）式が得られるから

$$
\begin{aligned}
& \log (0 \cdot 25-x)\left(4-\frac{12 \cdot 01}{47 \cdot 90} x\right) \\
& =-\underset{4 \cdot 575 \times 1473}{44000}+\frac{21 \cdot 74}{4 \cdot 575} \cdots
\end{aligned}
$$

（10）式を解けば， $x=0.2450 \%$

公に

$$
\mathrm{Ti}=0.0050 \%, \underline{\mathrm{C}}=3.9384 \%, \mathrm{TiC}=0.30 \text {. }
$$

同様にして種々の温度にわける平衡値を求めるこ己 きそこの結果を Fig. 1 亿実線で示しだ。

\section{(2) $\mathrm{Ti}+\underline{\mathrm{N}}=\mathrm{TiN}(\mathrm{s})$ の平衡}

$$
\begin{aligned}
& \mathrm{Ti}(\mathbf{s})+1 / 2 \mathrm{~N}_{2}(\mathrm{~g})=\mathrm{TiN}(\mathbf{s}) ; \\
& \Delta \mathrm{F}_{10}^{0}=-80300+21 \cdot 0 \mathrm{~T} \\
& \mathrm{Ti}(\mathrm{s}) 1 / 2 \mathrm{~N}_{2}(\mathrm{~g})=\text { 'TiN'(s)s.c.; } \\
& \Delta \mathrm{F}_{11}^{0}=-80250+22 \cdot 20 \mathrm{~T} \quad\left(298 \sim 1155^{\circ} \mathrm{K}\right)( \\
& \Delta \mathrm{F}_{12}^{0}=-80930+22^{\circ} 79 \mathrm{~T} \quad\left(1155 \sim 1500^{\circ} \mathrm{K}\right)(13) \cdot
\end{aligned}
$$

Pearson-Ende そよると（12)，(13）式の正確度は士 $3 \mathrm{kcal}$ 以下である. しか子(11) 式と（12）式（13）式 とは $1600^{\circ} \mathrm{C}$ 以下では $3 \mathrm{kcal}$ 以内でよく一致している から計算には（11）式を用いるととにした。 $1 / 2 \mathrm{~N}_{2}(\mathrm{~g})=\mathrm{N}_{l}(1 \%) ; \Delta \mathrm{F}_{18}^{0}=2580+5 \cdot 02 \mathrm{~T} \cdots \cdots(14)^{5}$ 


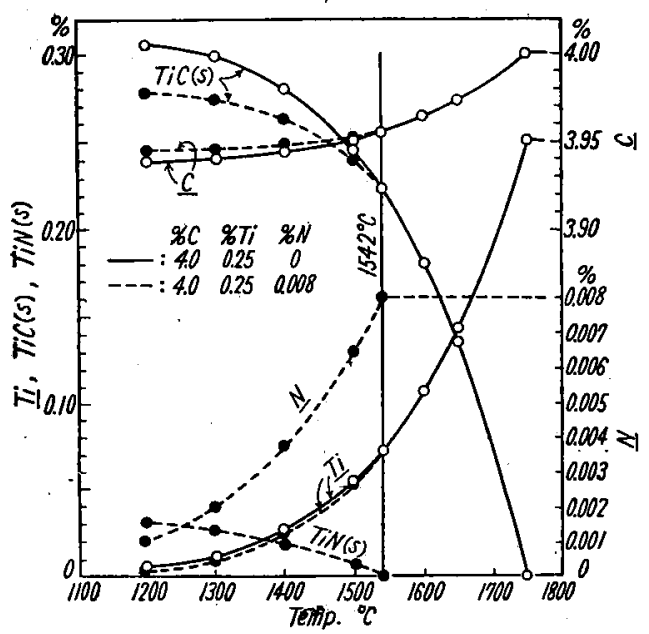

Fig. 1. Relation between the equilibrium contents of $\mathrm{Ti}, \mathrm{C}, \mathrm{TiC}(\mathrm{s}) \mathrm{TiN}(\mathrm{s})$ and temperature.

$$
\begin{aligned}
& (11)-(3)-(14) \\
& \underline{\operatorname{Tl}}_{l}(1 \%)+\underline{\mathrm{N}}_{I}(1 \%)=\mathrm{TiN}(\mathrm{s}) ; \\
& \Delta \mathrm{F}_{14}^{0}=-75880+26.98 \mathrm{~T} \ldots \ldots
\end{aligned}
$$

吃光に

$$
\underline{\operatorname{Til}}(0 \cdot 25 \%)+\mathrm{N}_{l}(0 \cdot 008 \%)=\operatorname{TiN}(\mathrm{s}) ;
$$

$$
\Delta \mathrm{F}^{0}=-75880+39 \cdot 32 \mathrm{~T}
$$

$\mathrm{Ti} ， \mathrm{~N}$ を含有する鉄浴に対する TiN の溶解度がきわ めて小であると仮定すれば， $\Delta \mathrm{F}_{15}^{0}=0$ ならしめる温度 $\left(1657^{\circ} \mathrm{C}\right)$ において (16) 式は平衡状態にあるととは前 と同様である. したがつて $1657^{\circ} \mathrm{C}$ 以下になると TiN が析出するのであるが種々の温度における Ti， N, TiN の平矣值は TiC の場合と同様にして計算するととがで きる.

（3）鉄浴に TiC，TiN が共存する場合

$\underline{\mathrm{C}}=4 \%, \underline{\mathrm{T} i}=0.25 \%, \underline{\mathrm{N}}=0.008 \%$ 老含有する鋳鉄 浴を高温度から徐泠するとまず $1751^{\circ} \mathrm{C}$ 加ら次式にした がつて TiC が析出し,

$$
\underline{\mathrm{T}} \mathbf{i}+\underline{\mathrm{C}}=\mathrm{TiC}(\mathrm{s})
$$

さらに温度か降下すると上式と次式にしたがつて TiC, TiN が同時飞析出する。

$$
\underline{T} \mathbf{i}+\underline{N}=\operatorname{TiN}(s)
$$

$\mathrm{TiC}$ と.TiN が同時に析出しはじめる温度を求める には次のでとくす礼ばよい.すなわち $\mathrm{N}=0.008 \%$ とし た場合に種々の温度において TiN が生成するために必 要な Ti 量 $x^{\prime}$ を求めると (15) 式汃 次式加得られ る.

$$
\log \left(x^{\prime} \times 0 \cdot 008\right)^{*}=-\frac{75880}{4 \cdot 575 \mathrm{~T}}+\frac{26^{*} 98}{4 \cdot 575} \cdots(17)
$$

また一方 $\underline{\mathrm{Ti}}=0.25 \% ， \underline{\mathrm{C}}^{\circ}=4 \%$ の愹鉄化おいて種々 の温度における TiC と平衡する Ti 量はFig: 1 亿示し たとおらりである. この両者の $\mathrm{Ti}$ 量が相等しくなる温度

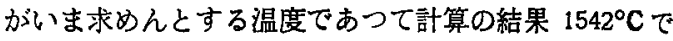
ある. $1542^{\circ} \mathrm{C}$ 以下の任意の温度にわける $\mathrm{Ti}, \mathrm{C}, \mathrm{N}$, $\mathrm{TiC}, \mathrm{TiN}$ の平唃值を求めるには次のでとくすればよ い.すすわち $\mathrm{Ti}=0 * 25 \%$ のうちで $\mathrm{TiC}$ となつた $\mathrm{Ti}$ 量を $x \%$, TiN となつたTi 量を $y$ \%とすれば $\mathrm{TiC}$ と なつたC 量は $\frac{12^{*} 01}{47^{*} 90} x$ ，TiN となつたN量は $\frac{14 \cdot 008}{47^{\circ} 90} y$ \%である.したがつて（9）式を導いたと同樣にして次 式が得られる。

$$
\begin{aligned}
& \underline{\mathrm{Ti}}_{l}\{(0 \cdot 25-x-y) \%\}+\underline{\mathrm{C}}_{l}\left\{\left(4-\frac{12 \cdot 01}{47 \cdot 90} x\right) \%\right\}=\mathrm{TiC}(\mathrm{s}) ; \\
& \Delta \mathrm{F}_{16}^{0}=-44000+21 \cdot 74 \mathrm{~T}-4 \cdot 575 \mathrm{~T} \\
& \times \log (0 \cdot 25-x-y)\left(4-\frac{12 \cdot 01}{47 \cdot 90} x\right) \cdots \cdots \cdots \cdots(18) \\
& \underline{T i}_{l}\{(0 \cdot 25-x-y) \%\}+\underline{\mathrm{N}}_{l}\left\{\left(0 \cdot 008-\frac{14 \cdot 008}{47 \cdot 90} y\right) \%\right\} \\
& \quad=\mathrm{TiN}(\mathrm{S}) ; \\
& \Delta \mathrm{F}_{17}^{0}=-75880+26 \cdot 98 \mathrm{~T}-4 \cdot 575 \mathrm{~T} \\
& \times \log (0 \cdot 25-x-y)\left(0.008-\frac{14 \cdot 008}{47 \cdot 90} y\right) \cdots \cdots(19)
\end{aligned}
$$

$T^{\circ} \mathrm{K}$ において両式がともに平矢状態にあれば (18)(19) 式の $\Delta \mathrm{F}$ はいずれも○であるから次式か得られる.

$$
\begin{aligned}
& \log (0 \cdot 25-x-y)\left(4-\frac{12 \cdot 01}{47 \cdot 90} x\right) \\
& =-\frac{44000}{4 \cdot 575 \mathrm{~T}}+\frac{21 \cdot 74}{4 \cdot 575} \\
& \log (0 \cdot 25-x-y)\left(0 \cdot 008-\frac{14 \cdot 008}{47 \cdot 90} y\right) \\
& =-\frac{75880}{4 \cdot 575 T}+\frac{26 \cdot 98}{4 \cdot 575}
\end{aligned}
$$

(20) (21) の連立方程式を $1542^{\circ} \mathrm{C}$ 以下の各温度につい て解けば $x$ および $y$ が求められてれから TiC, TiN の量が得られる. 計算の結果は Fig. 1 亿 破線で示したとおりである.

\section{III. $\mathrm{TiO}_{2}(\mathrm{~s}), \mathrm{TiO}(\mathrm{s})$ および $\mathrm{TiS}(\mathrm{s})$ の生成温度}

鼠鋳鉄中の○の含有量については現在正確に知られて いないが以下次の仮定を設けててれらの化合物が含 $\mathrm{Ti}$ 鼠鉡鉄浴中に独立相として生成する概略の温度を算出す

註 *この $x^{\prime}$ は (9) 式の $0.25-x$ k等しい. 
るととにした。

（仮定1）鋳鉄浴に Table.1亿示すように Ti=0.25 $\%, \mathrm{~S}=0.03 \%, \mathrm{O}=0 \cdot 002 \%$ が含有されている.

(仮定 2) 上記成分の鉡鉄浴汃ら析出する酸化 $\mathrm{Ti}$ お よひ硫化 $\mathrm{Ti}$ は $\mathrm{TiO}_{2}, \mathrm{TiO}$ および TiS で示される 代合物である.

（仮定 3）乙れらの化合物の鋳鉄浴に対する溶解度は

年である。

$\mathrm{TiO}_{2}$, TiO の標準生成自由エネルギーはそれぞれ次 式で与光られている.

$$
\begin{aligned}
& \mathrm{Ti}(\mathrm{s})+\mathrm{O}_{2}(\mathrm{~g})=\mathrm{TiO}_{2}(\mathrm{~s}) ; \\
& \Delta \mathrm{F}_{18}^{0}=-217500+41^{\circ} 4 \mathrm{~T} \\
& \mathrm{Ti}(\mathrm{s})+1 / 2 \mathrm{O}_{2}(\mathrm{~g})=\mathrm{TiO}(\mathrm{s}) \text {; } \\
& \Delta \mathrm{F}_{19}^{0}=-122300+2 \mathrm{l} \cdot 3 \mathrm{~T} \\
& 1 / \mathrm{O}_{2}(\mathrm{~g})=\underline{\mathrm{O}}_{l}(1 \%) ; \Delta \mathrm{F}_{20}^{0}=-28220-0.57 \mathrm{~T}
\end{aligned}
$$

次比

$$
\begin{aligned}
& \text { 吃に（3）(22）(24）および（3）(23）(24）式から } \\
& \mathrm{TiO}_{2}(\mathrm{~s})=\underline{\mathrm{Ti}_{i}}(1 \%)+2 \underline{\mathrm{O}}_{l}(1 \%) ; \\
& \Delta \mathrm{F}_{21}^{0}=154060-53 \cdot 54 \mathrm{~T} \\
& \mathrm{TiO}(\mathrm{s})=\underline{\mathrm{Ti}}_{l}(1 \%)+\underline{\mathrm{O}}_{l}(1 \%) ; \\
& \Delta \mathrm{F}_{22}^{0}=87080-32 \cdot 87 \mathrm{~T}
\end{aligned}
$$

（25）および（26）式を基として $\underline{\mathrm{Ti}}=0 \cdot 25 \% ， \underline{\mathrm{O}}=$ $0.002 \%$ なる成分の鋳鉄浴汃ら $\mathrm{TiO}_{2}(\mathrm{~s})$ および $\mathrm{TiO}(\mathrm{s})$ が生成する温度を計算すると， $\mathrm{TiO}_{2}(\mathrm{~s}) ： 1629^{\circ} \mathrm{C}$, TiO(s): $1542^{\circ} \mathrm{C}$ となる.

次有川一成田氏 ${ }^{12}$ 亿よると

$$
\begin{gathered}
\mathrm{Ti}_{l}(1 \%)+\underline{\mathrm{S}}_{l}(1 \%)=\mathrm{TiS}(\mathrm{s}) ; \\
\Delta \mathrm{F}_{28}^{0}=-122820+51 \cdot 46 \mathrm{~T}
\end{gathered}
$$

（27）式を基にして $\underline{\mathrm{T}} \mathbf{i}=0.25 \% ， \underline{\mathrm{s}}=0.03 \%$ なる成分 の錆鉄浴加ら TiS(s) が生成する温度を求めると 1725 ○Cとなる. これらの温度の求め方は前記と同様である 加ら省略する.

\section{IV. 考察}

以上の計算結果加ら考察すると Table 1 亿示す成分 の錆鉄浴を高温度から徐冷するとまず $1751^{\circ} \mathrm{C}$ のでとき 高温度で TiC(s) の析出が始まりその後 TiS(s), $\mathrm{TiN}(\mathrm{s}) ， \mathrm{TiO}_{2}(\mathrm{~s}) ， \mathrm{TiO}(\mathrm{s})$ 等の析出が続いて起る可 能性が認められるが $\mathrm{S}, \mathrm{O}, \mathrm{N}$ の含有量は微量であるか ら鏻鉄内比出する $\mathrm{Ti}$ 化合物は大部分 $\mathrm{TiC}(\mathrm{s})$ であ

注 原著者の粘果に多少の篮正を加えてある.
るととが容易に推定されるたとえば $1400^{\circ} \mathrm{C}$ おるび $1450^{\circ} \mathrm{C}$ 亿おいて平衡状態にある $\mathrm{C}=4.0 \%, \quad \mathrm{Ti}=0.25$ $\%, \mathrm{~N}=0.008 \%$ なる成分の䤻鉄浴中に存在する $\mathrm{TiC}$ (s) および TiN(s) の形態の Ti の全 Ti 含有量に対する 割合を Fig. 1 から求めると Table 2 のでとくであ 了.

Table 2. Ratio of $\mathrm{Ti}$ as $\mathrm{TiC}$ and $\mathrm{TiN}$ forms to total $\mathrm{Ti}$ at $1400^{\circ} \mathrm{C}$ and $1450^{\circ} \mathrm{C}$.

\begin{tabular}{c|c|c|}
\hline \multirow{2}{*}{$\begin{array}{c}\text { Temp. } \\
\left({ }^{\circ} \mathrm{C}\right)\end{array}$} & \multicolumn{2}{|c}{ Ti $(\%)$} \\
\cline { 2 - 3 } & Ti as TiC form & Ti as TiN form \\
\hline 1400 & 84 & 6 \\
\hline 1450 & 81 & 4 \\
\hline
\end{tabular}

以上の計算結果は勿論正確なものではない，その第」 の原因は本計算を問題の Ti 化合物はすべててれらの化 合物の化学分子式で表わされる物質として析出するもの と仮定して行つた点にある.ととろがたと元ば Hume et a1 ${ }^{13)}$ が TiC と TiN とはすべての割合で固溶体を 形成するといつているように含 $\mathrm{Ti}$ 鋳鉄浴中に析出する Ti 化合物は仮定したような簡単な化合物でなくして複 雑な成分の化合物あるいは固溶体かる知れない。しかし 广がら著者等の研究方によつて普通成分の S-H 録鉄に 含有されている炭化 Ti に関する限り大部分純粋に近い TiC なる化合物であるととが推定されている．第2の

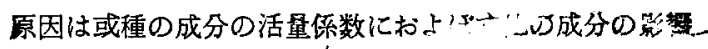
を全く無視して行つたてどこある．鋳鉄浴に含有される 諸成分の活量保数を定めるのに必要な相互作用係数がま だ正確な計算ができる程充分に知られていないからであ る.したがつてとれによる誤差はある程度大きいととは 止むを得ない. 第 3 の原因は鋳鉄浴より析出する前述の Ti 化合物は鋳鉄浴に全く溶解しなといとを仮定したて とである.しかしながら現在のところ Ti 化合物の溶解 度の程度を知る正確な実験的資料が見当らないので仮定 が計算結果にいかなる程度の愦差をもたらすかは予想さ れない.

Tofaute-Büttinghaus ${ }^{14)} の \mathrm{Fe}-\mathrm{C}-\mathrm{Ti} 3$ 元系状態図 に関する研究によると本計算の対象とした $\mathrm{C}=4 \cdot 0 \%$, $\mathrm{Ti}=0.25 \%$ の鋳鉄は $1400^{\circ} \mathrm{C}$ において液相単一相の分 野にあつて TiC(s)は存在していないととになつている。 この点は著者等の計算結果と大いにてとなつているが, 同氏等はかような成分のものについてはおそらく実験を 行つておらず，したがつて同氏等によつて示されている 上記の点にういては大なる疑問があると考えられる。 
なお，著者等が前研究において造つた砂型錆造のS-H 鋳銑試片の TiC の形態の Ti は Table 2 に示した量 におおむね近く全 $\mathrm{Ti}$ 含有量の $80 \%$ 内外であることは 興味ある事実である.乙れは本計算結果に密接な関係が あるこ上が推察される.現在本計算結果を確める実験を 行つているのでその結果をもつて上記の関係を明らかに しようと思う。.

\section{V. 総括}

1) $\mathrm{Si}, \mathrm{Mn}$ および $\mathrm{P}$ 以外化 $\mathrm{C}=4.0 \%, \mathrm{Ti}=0.25$ $\%, \mathbf{S}=0.03 \%, \mathrm{~N}=0.008 \%, \mathrm{O}=0.002 \%$ なる成分の 鋳鉄浴が徐冷する間に TiC(s) および TiN(s) が析出 する道程を熱力学的に明らかにした。

.2）1）の計算によると $1400 \sim 1450^{\circ} \mathrm{C}$ において平衡 状能にある上記成分の鋳鉄浴中には全 $\mathrm{Ti}$ 含有量の約 80 $\% の \mathrm{Ti}$ が $\mathrm{TiC}(\mathrm{s})$ の形態において存在するととを知 دた.

3）上記成分の鋳鉄浴からそれぞれ $\mathrm{TiO}_{2}(\mathrm{~s}), \mathrm{TiO}(\mathrm{s})$ あるいは TiS(s) が生成する温度を熱力学的計算によつ て求めた

4) 本計算結果の正確度を種々の点から検討した。

5）上記の計算結果は余り正確とはいえないかてれに よつて S-H 鋳鉄浴中における Ti の挙動の概略の傾向 を知るととができた。(昭和 31 年 8 月寄稿)

\section{文䓟}

1）沢村厷，津田昌利，铁と缺，40 (1954) 622

2）沢村密，津田昌利：鉄と鎆，38 (1952) 150

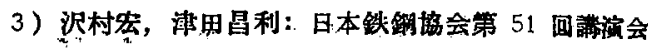
亿㕲いて哞表（1956年4月),本誌奇稿中

4) F. D. Richardson: J. Iron \& Steel Inst.; 175 (1953) 33

5) A.I.M.E.: Basic Open Hearth Steel Making, (195i) 638

6)同上 669

7)同上 573

8) J. Pearson and V. J. C. Ende: J. Iron \& Steel Inst., 175 (1953) 52

9) F. D. Richardson and Jeffes: J. Iron \& Steel Inst., 160 (1948) 261

10) O. Kubaschewski and W. A. Dench: J. Inst. Metals, $83(1953 / 54) 87$

11) J. Chipman, J. C. Fulton, N. Gok un and G. Casky, Jr.: Acta Metallurgica, 2 (1954) 439

12）有川正康，成田貴一：鉄と触，39 (1953) 352

13) W. Hume-Rothery, G. V. Raynon and A.J. Little: J. Iron \& Steel Inst., 145 (1942) 129

14) W. Tofaute und A. Büttinghaus: Arch. Eisenhüttenw., 12 (1938) 33 